\title{
1. What is paradox? Tensions, contradictions and oppositions in organization studies
}

Indeed, even at this stage, I predict a time when there will be mathematical investigations of calculi containing contradictions, and people will actually be proud of having emancipated themselves from consistency.

(Wittgenstein, 1964: 332)

Paradox, once seen by those who write about the organizational machinery as a defect or an extravagant form of inconsistency, is represented in contemporary organizational scholarship as a condition of complex organization. Organization is full of paradox: change vs. stability, planning vs. emergence, exploration vs. exploitation, to name only some of the most frequently discussed. From what is increasingly known as a paradox perspective, organizations are more than the site of occasional and specific paradoxes; they are intrinsically paradoxical. These paradoxes are not just situations of rational choice between alternatives if only because organizing may be a means for emotional and political expression (Petriglieri \& Petriglieri, 2020).

Binary oppositions demanding choice are replaced in paradox perspectives by dualities that necessarily coexist. What is a paradox? How can organizations be understood through a paradox lens? To discuss this question, the book can be read as a contribution to a discipline of aporetics (from the ancient Greek aporía, impassability, contradiction), whose goal consists in teaching us how to live with contradiction and paradox (Rescher, 2001). Plurality, in terms of goals, expertise and logics, pervades organizing (Berti, 2021). Rather than being a sign of dysfunction or inconsistency, contradictions are to be seen as a constitutive feature of any complex system. Paradoxes, rather than being conceits of organization theorists' excessive search for novelty, should be considered a lens or a tool that managers may use to make sense of and manage organization.

This chapter introduces key definitions and ideas developed by organizational paradox scholars, which constitute the currently agreed upon conceptual core of paradox theory. It explains why paradox deserves to be studied and offers a brief history of the evolution of the concept and of the vital scholarly community studying paradox. The chapter also includes a discussion of the origin of paradoxes along with different uses of the concept. 


\section{BOX 1.1 THE FEAR OF PARADOX}

Paradox has traditionally been viewed as an invitation to irrationality, a facet well explored in the artistic realm by artists such as Escher (2000). Consider Tetenbaum's (1998: 23) description of the dangers of such a perspective: "It is human nature to prefer, to seek out, and even to expect certainty. Paradoxes threaten that world order. A common way to handle this unpleasant state is to 'fix' on one polarity and to see the world as 'either-or' rather than to reconcile the two polarities with 'both-and' thinking." The fear of paradox is possibly rooted in the engineering origins of organization theory (Shenhav, 1995). For classical organizational theorists organizing was an exercise in uncertainty reduction. Organization implied the elimination of uncertainty. Paradox, by contrast, refers to the acceptance of ambiguity and tension. From a classical perspective, paradox is the expression of disorganization, of 'noise' in the organization system.

Management and organization studies is a field that favours the rational and expresses its distaste for the irrational. Nonetheless, it is simultaneously open to fads and fashions (Benders \& Van Veen, 2001), as well as to what Gimpl and Dakin (1984) termed the appeal of magic, in the form of spells cast against the uncertainties of futures unknown, such as long-range strategic planning, or learning premised on superstition, perhaps caused by the need for control. Intolerant of ambiguous situations and the uncertainties of futures unknown and their contradictions, managers can invoke 'magical' techniques to gain an illusory sense of control, fulfilling an important psychological function. More realistically, perhaps, recent invocations of agile organizations assume that organizations do need to learn how to improvise and accept their vulnerability in face of change.

\section{WHAT IS PARADOX?}

Organizational life is increasingly described as being rife with paradox. Following a well-known definition, paradox refers to "contradictory yet interrelated elements that exist simultaneously and persist over time" (Smith \& Lewis, 2011: 386; see also Box 1.1). Paradox marks those processes characterized by interlocking oppositions that cannot be willed away, something well expressed in the name paradoxes were given during the Middle Ages: insolubilia. The interlocked nature of oppositions is important as not every tension or contradiction corresponds to a paradox. For example, the make vs. buy decision is a dilemma, not a paradox. The two options are independent. But change and stability are better viewed as paradox: one element defines the absence of the other; change is the opposite of stability, yet neither can be understood 
without the other, as they compose a duality (see Glossary). As Farjoun (2010) explains, one is understandable only in the presence of the other. Their relation is dynamic; they mutually constitute each another as organizations evolve. It is this interlocked dynamic relationship that constitutes paradox.

\section{BOX 1.2 DEFINITIONS OF PARADOX}

There are many definitions of paradox. Here is a sample:

"A paradox is a stretch of reasoning that leads from apparently impeccable premises by apparently straightforward steps of reasoning to an unacceptable conclusion. Usually (though not always) the unacceptability of the conclusion is that it is contradictory" (Goldstein, 1996: 299).

"A paradox is an argument with premises which appear to be true and steps which appear to be valid, which nevertheless ends in a conclusion which is false" (Priest, 1979: 220).

Paradox "denotes contradictory yet inter-related elements-elements that seem logical in isolation but absurd and irrational when appearing simultaneously" (Lewis, 2000: 760).

"Paradox may refer to: 1) claims contrary to common opinion, often suggesting that the statement is incredible, absurd, or fantastic, but sometimes with a favorable connotation as a correction for ignorance; 2) a statement that seems self-contradictory, but which is actually well-founded; 3) a statement that involves a genuine contradiction; 4) in logic a conclusion based on acceptable premises and sound reasoning that nonetheless is self-contradictory" (Bufford, 2006: 531).

Competing demands recur at every organizational level from the strategic apex to the operational base (a topic discussed in Chapter 5). Top managers embed paradoxes in their organization's strategies for exploring and exploiting, organizing the long term and the short term, cooperating and competing, disrupting their organizations while reinforcing their value (Smith, 2014). At the operational level, in the call centre, operators are supposed to deliver courtesy, efficiency and effectiveness, comprising what Clark et al. (2019) call triple trade-offs. The most successful operators are able to synthesize competing demands in a fruitful way, finding synergies between what at first appears incompatible. New leaders are expected to prove themselves quickly while knowing that quick results are an inherently dangerous pursuit (Van Buren \& Safferstone, 2009). As Bahcall (2019) put it, managers must equilibrate roles as metaphorical artists and soldiers in their organizations to succeed. Artists create ideas and designs to gain an advantage, while soldiers are drilled to perfect routines. If the organization employs too many soldiers it will repeat 
the same routines; too many artists will lead to creativity in design, but these diverse designs will need to be applied in the complexity and messiness of the 'battlefield'.

Paradoxical tensions, according to Smith and Lewis (2011) may be exacerbated by tendencies such as digitalization and the globalization of the world economy, creating ever more febrile organizational environments. In the face of these tensions new challenges emerge, such as the need to embrace new digital business models and organizational designs that must necessarily coexist with existing models. Globalization creates awareness of different modes of managing and organizing. For instance, in some settings leaders can be both authoritarian and benevolent, a seemingly paradoxical combination (Cunha et al., 2021). One vivid example is offered by Jared Diamond in his book Collapse (2005). This author describes how the decisions of Joaquin Balaguer, the despotic political leader who dominated the political scene in the Dominican Republic in the second half of the 20th century, were instrumental in preserving the nation's environment, especially in comparison to the ecological devastation experienced by the neighbouring Haiti. An equivalent capacity to navigate contradiction has been associated with former Colombia President and Nobel Peace Prize winner, Juan Manuel Santos, whose approach oscillated between acting as a hawk and a dove (Ortiz, 2020).

Evidence shows that successful organizations have learned how to master the art of the paradox. Marvel, for example, has used continuity and renewal, positive and negative emotions to sustain its blockbuster machine (Harrison, Carlsen \& Skerlavaj, 2019). Yet, the idea of 'mastering' paradox is treacherous. Organizations change over time because the tensions they face are themselves dynamic. As organizations tackle one tension, they open other tensions. As governments in Southern Europe were forced to embrace financial discipline to balance their accounts, they unbalanced the established equilibria in a number of services, such as healthcare, a process whose consequences became clearer only years after the measures were taken. Once equilibrium was more or less restored, the COVID-19 pandemic forced these (and other governments) into rethinking the efficiency-resilience trade-off. Equilibrium, therefore, is dynamic and precarious, implying cycling back and forth. In cases where none of the phases overwhelms the others, the system can be said to remain in a state of dynamic equilibrium (Bahcall, 2019). Yet this equilibrium is necessarily precarious, as one phase may at some point, for some reason, become dominant.

\section{WHY STUDY PARADOX?}

Scholars have embraced the paradox view of organizations for several reasons. Paradoxes are a pervasive presence in organizations. They do not constitute 
an anomaly but rather something normal, even ordinary. Studying paradox facilitates a departure from dualistic views of organizations, in which more of one force represents less of another, to a view that is more complex but also closer to philosophical views of the world that underline interdependence, with a focus on duality. From a duality perspective, organizational opposites form one another, instead of involving either-or types of challenges. A paradoxical view is therefore an invitation to constitute organizations as tensions that can be generative or debilitating, composed of dualities that offer fresh forms of understanding as well as complementarities between moments of balance and imbalance. The setting of paradox theory, in other words, is a Protean world, one not only with the potential for predictability but also for surprise - just like the 'real world'. Unsurprisingly, managing complex paradoxes successfully with simple recipes is impossible. In spite of the attractiveness of both-and balancing (Smith, Lewis \& Tushman, 2016), paradox may sometimes imply temporary either-or imbalance (Bednarek, Chalkias \& Jarzabkowski, 2020).

\section{BOX 1.3 PARADOX IN THE ARTS: A SOURCE OF AESTHETIC DELIGHT}

Artists have explored the potential of paradox to discuss the human condition and experience from multiple angles, of which we explore three possibilities opened by Kafka, Carroll and Escher.

Kafka. The work of Franz Kafka provides some of the best illustrations of paradox in literature. His books offer vivid accounts of how bureaucracy can become monstrous. In the labyrinthine organizations he describes, humans feel that organizations gain a life of their own that in its inscrutability and perplexity runs against the interests of the general public or, at least, those that are powerless before it. His works, namely the short story In the Penal Colony, anticipates the bureaucratic work with which modern organizations created death camps normalizing evil (Clegg et al., 2013; see also Chapter 4 on the dark side of paradox).

Lewis Carroll. As Nicholas Rescher (1960) pointed out, Lewis Carroll's Alice in Wonderland and the respective gallery of characters it presents, tests the limits of logic. Wonderland is a very different world, the logic of which differs from any known or depicted reality. The point, however, is that real organizations frequently resemble Wonderland rather more than any known reality in which people are easily capable of believing as many as 'six impossible things before breakfast', especially at away days in which a form of Wonderland becomes imagined into schemes and dreams.

Escher, Parmigianino, Uccello. Visually Escher's subtle transformations and 'impossible objects' offer one of the most attractive depictions of para- 
dox. The worlds of Escher present intriguing transformations: they provide examples of visual paradox. However, the introduction of visual paradoxes is not a 20th-century invention: the 16th-century painter Parmigianino also included in his works "background elements (such as columns) which are inconsistently organized, playing. Although these paintings are not self-referential as are typical verbal paradoxes, they are equivalent to the paradoxical form 'true if and only if false' in that they contain incompatible or circular elements which express a feeling of unease" (Duran, 1993: 239). Similarly, the 15th-century artist Paolo Uccello anticipated Cubism, creating images that "were truer when they were less true to life" (Argan, 1968: 186).

\section{PARADOX IN ORGANIZATION STUDIES: A VERY BRIEF HISTORY}

The idea of paradox as a constitutive feature of its subject matter has been historically discounted by management and organization theorists, but the idea is gaining momentum. As pioneering paradox scholars Poole and Van de Ven (1989) point out, most theories of organization try to build internally consistent arguments. Less attention has been paid to the potential for theory building of the same phenomena that focuses on tensions, oppositions and contradictions. Organizations, as noted in the Introduction, have been largely imagined as spaces of order and rationality. Conceiving of them as paradoxical poses a threat to imagined order, a threat that began to emerge in the literature in the 1970s and 1980s.

The 1970s and before: Paradox as aberration. The role of tension in management and economics is possibly as old as the study of these topics. Class conflicts in the Marxist tradition, or the tension between managers and workers in Taylor's (1911) analysis of processes such as soldiering, offer examples of irreconcilable oppositions giving rise to tensions as a topic for management studies. While these old themes in research are well established and reconciled (Braverman, 1975), the study of paradox per se is a more recent phenomenon.

Whenever apparent paradoxes were detected in bureaucratic organizations, they were approached as puzzles to be solved. The contradictory evidence showing that more competitive groups are less productive, whereas more competitive individuals are more productive, was explained by Blau (1954) as demonstration of the importance of social cohesiveness and cooperative norms for productivity. Similarly, the paradoxical observation that increases in delegation of authority (decentralization, or reduction of control) are associated with an increase in standardization (which amounts to centralization, or increase in control), is explained by Perrow (1977) as an apparent contra- 
diction caused by a confusion between different forms of control (direct and indirect) and that effective management is achieved by an appropriate mix of different forms of control.

The 1980s: Paradox as phenomenon. The first substantive engagement with interdependent tensions was offered by Benson (1977). His important and still highly influential analysis described organizations as dialectical processes, with tension occurring because of the embeddedness of organizations in social totalities. He defended the thesis that organized social processes are contradictory. Social totalities are systems in which a plurality of interests coexist, necessarily infusing organizing with contradiction and opposition. Phenomena such as organizational politics and resistance to change are not organizational anomalies but a necessary expression of this plurality. The dialectical view offered by Benson (1977) is still bearing fruit in several works analysing the process through which tension introduces novelty into organizational systems (Clegg \& Cunha, 2017; Farjoun, 2019). The relationship between dialectics and paradox has been subject to recent scrutiny (Hargrave, 2021; Hargrave \& Van de Ven, 2017). Overall, the dialectical perspective helps to explain why persistent paradox does not produce 'stuckedness' (Vignehsa, 2014) in the form of paralysing tensions that are never resolved. Contradictions framed as paradoxical potentially may be transformed through synthesis, despite being persistently imperilled by forces outside managerial control.

Among the pioneers to explicitly explore paradox as an organizationally relevant concept were Quinn and Cameron (1988) and Poole and Van de Ven (1989). These authors discussed paradox not as noise to be removed but as a characteristic of organization - a lens with which to explore contradiction. Poole and Van de Ven justified the metatheoretical potential of paradox through focusing on tension and opposition to expand other theories of organizations. While phenomena such as organizational change and institutionalization processes do not have to be approached from a paradox perspective when analysed from the point of view of the contradictions they necessarily trigger, some of their attributes become more transparent. If the tension between existing power structures and emergent power relations are ignored, change becomes more difficult to explain. As Poole and Van de Ven (1989) explain, tensions and contradictions constitute one possible source of change that can be analysed along with other sources.

The idea that paradox was not a sign of dysfunction but rather a manifestation of organizational complexity was proposed by Quinn and Cameron (1988). Cameron (1986) discussed the idea of organizational effectiveness as paradox; with the competing values model (Cameron et al., 2014) he presented organizational culture as a form of balancing competing cultural orientations. Where organizational culture is dominated by a singular sense of what is valuable it will potentially create an unbalanced organization. The push-pull 
between different values is necessary to nurture contradictory but necessary attributes, such as internal solidarity, a focus on metrics and results, rule clarity and a measure of innovation. When one value dominates and overrides the others the system becomes compromised. More recently, Cameron presented positive organizational scholarship as a paradoxical journey (Cameron, 2008), an idea subsequently expanded by Cunha, Rego, Simpson and Clegg (2020), as well as in Chapter 3 of this book.

Smith and Berg (1987), in exploring the tensions inherent to teamworking, pioneered the study of teams as paradoxical. Inspired by psychodynamic theory, they noted the inherent paradoxicality of group life. Teams are simultaneously spaces in which people expect a measure of integration and differentiation, aiming to satisfy their needs of belonging without compromising unique individuality. Also inspired by a psychodynamic perspective, Kets de Vries (1995) explored paradoxes of organizations and leadership to show that beneath the façade of rationality, organizations and their leaders express a number of themes that would remain inexplicable if representing organizations as strictly rational phenomena. These efforts can be critical to understanding how teams manage to articulate a number of simultaneously occurring paradoxes (Silva et al., 2014) while creating and recreating a viable team identity. As Murnighan and Conlon (1991) revealed, while these tensions may be implicit or explicit, they need to be articulated for the team to perform at a high level. The pioneering work of Smith and Berg resonates with more recent research by Edmondson and Lei (2014) on how successful teams balance psychological safety and accountability. These pioneering paradox scholars saw contradiction and opposition not as a categorization mistake or an aberration, but as 'real' phenomena, ordinary implications of organizing plurality.

The 1990s: Paradox as signal of complexity. The adoption of a complexity perspective by authors such as Stacey (Stacey et al., 2002) and Eisenhardt (2000), and the exploration of organization as process by scholars such as Tsoukas and Chia (2002), offered a new perspective on paradox as an organizational phenomenon. Paradox was being approached obliquely, as an outcome of the complexity of organizations. Organizational processes are recognized as being complex, such that, to preserve vitality, organizations need to remain at the 'edge of chaos', the interstices in which order and disorder collide and coexist. Eisenhardt explained how organizations engage in high degrees of complexity to adapt to markets that shift relentlessly (Brown \& Eisenhardt, 1997, 1998). Eisenhardt's work described organizations as needing to define simple rules in order to adjust to complex environments. The notion of simple rules as heuristics that help to cope with what can otherwise be paralysing complexity was further developed by Sull and Eisenhardt (2015) 
as a requirement for remaining organized without becoming rigid (excessively structured) or disorganized (insufficiently structured).

Robert Cooper (1986) developed the idea that it is better to conceptualize organizations as processes that exist in relation with other organizations rather than assuming that they are self-sufficient machines. Cooper's work on the tension between organization and disorganization anticipated several future research agendas. A debate was launched in the 1990s concerning the need to complexify (Tsoukas, 2017) or to simplify (Sull \& Eisenhardt, 2015) organizations, if they are to thrive in hypercompetitive economies. Other important developments in a paradox theory of organizations at this time included Westenholz's (1993) embrace of paradoxical modes of thinking. Overall, the 1990s viewed paradoxes as means for understanding the embeddedness of organizations in incessantly changing and complex environments.

Another central contribution to the study of paradox as an expression of complexity is offered by the work of the German sociologist, Niklas Luhmann. Considering organizations as social systems that must mark their difference from their environments, they engage in a process of selection that reduces environmental complexity (Luhmann, 1995a). Such selection processes generate a first paradox: while organizing simplifies reality to enable action, at the same time it generates new contingencies, information and differences, deriving either from "an increase in differentiation or ... a change in the form of differentiation" implicated in organizing (Luhmann, 1995a: 21). Moreover, organizations can be considered as "systems that consist of decisions and that produce the decisions of which they consist, through the decisions of which they consist" (Luhmann, 1992: 166, cit. in Seidl \& Mormann 2014: 137). These decisions are intrinsically paradoxical, in that they both imply and exclude the possibility of alternatives (Cooren \& Seidl, 2020). To hide these contradictions, organizations respond with attempts to 'deparadoxify' (Luhmann 1995b: 46), by shifting attention from the content of the decision to its premises (i.e. the logic followed), or by attributing it to a decision maker, thus emphasizing their motivations. Therefore, organizational decisions cannot be 'simple' choices if only because not considering complicating aspects, such as human motivations and chains of premises, would reveal their intrinsic paradoxicality (Luhmann, 2018).

A third organizational paradox described by Luhmann derives from communication, another essential component of social systems. Communication requires, in addition to information and utterance, also understanding; thus, the listener is the one who determines the meaning of the communication and decides whether to accept or reject it in the context of other communications (Luhmann, 1986). The process of understanding is difficult to observe and predict, which undermines the structure of expectations on which social systems are based (Luhmann, 1995a). To deal with this problem, social 
systems use actions as a connecting device. This is because "actions appear self-defined and do not presuppose other actions" (Seidl, 2004: 12), which enables organizations to separate actions and to attribute them to specific agents. However, this simplification strategy increases separation of actions and agencies, paradoxically increasing complexity in the system. In other words, in organizations individual members are viewed only as vehicles for performances, producers of tangible deliverables; the other aspects that make human experience meaningful (intentions, emotions, interpretations et cetera) are instead ignored (with the intent of simplifying things). Yet, this forced reduction of complexity triggers tensions, conflicts and contradictions that feed complexity back into organizational dynamics.

The 2000s: Paradox as opportunity. The new millennium brought a new level of attention to paradox theory and practice, implying that good management may entail working with paradox (Fiol, 2002). In the early years of the decade, one of the authors of this book organized an initial volume dedicated to management and organizational paradoxes (Clegg, 2002) and Marianne Lewis made a number of pivotal contributions. She offered a 'comprehensive guide' to the field (Lewis, 2000), also pioneering the examination of the potential of paradox for business education (Lewis \& Delher, 2000). In the following years she explored several facets of paradox in organizations including the paradoxes of innovation (Andriopoulos \& Lewis, 2009), leadership (Lewis et al., 2014) and governance (Sundaramurthy \& Lewis, 2003). Lewis later collaborated with Wendy Smith in developing a view that paradox is not a lens with which to explore some other phenomenon but an important organizational phenomenon in its own right.

The article by Smith and Lewis (2011), 'Toward a theory of paradox: a dynamic equilibrium model of organizing', consolidated the parameters of a paradox perspective on organizations. It presented paradox as a stimulus of processes potentially creating dynamic equilibrium for organizations. Paradoxes could stimulate virtuous circles from which cycles of belonging, performing, learning and organizing could be generated as these paradoxes coevolve (Jarzabkowski et al., 2013). Equally, the response to paradoxes might be a vicious cycle of alienating, stalling, ignoring and disorganizing. Smith et al. (2016) subsequently explored paradox as a managerial tool, confronting managers with opportunities to gain value from organizational tensions. Doing so, they suggest, entails not making an either-or choice but one that promotes what they refer to as a 'both-and' approach. Accordingly, paradoxes must be approached not as something to overcome but as a normal state of affairs. In their normalcy, paradoxes in competitive landscapes that are ambiguous and rich in tension become a potential source of temporary advantage when they are embraced rather than rejected. 
The 2000s saw paradox become a more widely adopted theoretical lens, in part because of parallel developments in organization theory. James March's work was significant. March's contributions to the study of organizations are major and long-lasting; through his work both the systematization and the poetization of organizations has thrived; the former through his Handbook (March, 1965 [2013]) and textbooks (March \& Simon, 1958), the latter through his playfulness in articles (March, 2006a, 2006b). Of his later works, perhaps none gained more traction (and certainly citations) than his analysis of the tension between exploration and exploitation in organizations (March, 1991). The paradoxes in his analysis of these tensions are evident. To survive, organizations need to find a way of maintaining both exploration and exploitation in tension rather than becoming fixated on one or the other: they must embrace both. If they do not, organizations risk being myopic. To avoid myopia, mixing the bodily metaphors, organizations must be ambidextrous or, staying with the optical metaphor, they need 20/20 binocular vision, focused on both exploration and exploitation.

Successful organizations cultivate ambidexterity (O'Reilly III \& Tushman, 2013). Managers in ambidextrous organizations work less at wholly controlling rationality but also strive to release imaginative potential. Leaders need to be able to nourish both poets and plumbers (March \& Weil, 2009). Too much poetry becomes delusional; too much plumbing and the organization will merely repeat itself. Therefore, leading is a dual task, one that implies both pragmatism as well as the search for beauty. March's earlier writings on topics such as foolishness contributed towards questioning the assumption that seeing the irrational side of organizing is itself irrational. He showed that the theoretical reduction of organizations to their rational side constituted a gross simplification of the complexity of organizations that involve opposite elements in a state of coexistence. Rationally, however, the notion of ambidexterity serves to keep the plumbers and the poets apart, something that characterized the distinction between March's poetry and contributions to science (Chytry, 2003). Suffice to say, March's contributions in the 2000s were critical for normalizing the idea that organizations can be considered paradoxical in a positive way. March was the organization theorist that brought the idea of paradox out of the dark and into the light as a central theme in explaining the functioning of organizations.

The 2010s: Expanding paradox theory. A hallmark of institutionalization in the realm of ideas is increasing specialization. Paradox theory was considerably institutionalized in the second decade of the 21 st century. In the 2010s, important literature reviews were produced (Putnam et al., 2016; Schad et al., 2016); a paradox theory handbook was launched (Lewis et al., 2017); a specialised anthology published (Farjoun et al., 2018); special issues organized (Smith et al., 2017; Bednarek et al., 2021; Lindgreen \& Maon, 2019; 
Waldman et al., 2019); as well as a standing stream maintained in the annual colloquium of EGOS. Putnam et al. (2016) observed the number of papers published increasing, reflecting a movement gaining aficionados. Intellectual investments were being made in a bet that they would yield interest and build capital. In the process, opposition, interdependence and persistence became the standard definition of what constituted a paradox. A community of scholarly practice was coalescing around the banner of paradox, nurtured via regular symposia attended by a cohesive group of scholars, including the movement's leading intellectual apostles (Wendy Smith and Marianne Lewis).

\section{BOX 1.4 CREATING A SCHOLARLY COMMUNITY: A COMMENTARY BY WENDY SMITH}

The early 2000s was both an exciting and a lonely time to write about paradox. I encountered insight about paradox as a doctoral student, while studying how top management teams manage change and innovation. This lens seemed like a perfect framework to help inform my thinking about the tensions these leaders encountered between exploration and exploitation. Luminaries in organizational theory had written key pieces to advance scholarship on paradox, setting the stage for future work to build on. Yet these pieces remained scant. In fact, many of these same scholars invested in advancing paradox theory offered caution. Paradox scholarship remained peripheral in the field, and therefore challenging to publish in top journals. Two things happened that motivated me to continue to publish in the field. First, Marianne Lewis published her article in the Academy of Management Review (2000), which won the best paper award that year. I asked her for advice, and we met at the Academy of Management in 2004. Our energizing conversation started an ongoing dialogue that continue to be a tremendous collaboration. Second, I joined the Strategy-as-Practice track of EGOS in Amsterdam in 2008, where I met Ann Langley, Paula Jarzabkowski and other colleagues committed to the power of a paradox lens. Paula, Marianne and I submitted a sub-track on paradox scholarship for EGOS 2010 in Portugal. We were overwhelmed by the response to the call for papers colleagues around the world interested in applying a paradox lens to a myriad of phenomena at various levels of analysis responded. Energized by the conversations and connections at the sub-track, the scholars there decided to continue to organize this community both online through a newsletter and social media, as well as through conference connections at EGOS, Academy of Management and other venues. These efforts sparked continued and expanded interest, connecting collaborators, while also advancing initiatives for special issues, handbooks, special conferences on paradox. 
Together this work advanced our insights about paradox, while building community and connection along the way.

This new maturity was expressed in a number of new angles. A central debate focused on the ontological and epistemological dimensions of paradox. It became accepted that paradoxes are ontologically inherent and epistemologically socially constructed, even if different authors gave more emphasis in highlighting one or the other facet. These two dimensions were often assumed rather than being positioned as topics for discussion. Towards the end of the decade scholars started to problematize the analytically constitutive features of the topic, invoking quantum theory (Hahn \& Knight, 2019), the role of supporting actors in interpreting paradox (Pradies et al., 2020) and micro-macro links (Schad \& Bansal, 2018). These discussions increasingly revealed the nested nature of paradox and a concern with analysing paradox critically.

Some research explored the limits of 'both-anding', assuming that in some cases competing demands may need to be viewed as trade-offs or dilemmas. When paradoxes are regarded as irresolvable dilemmas they can stimulate management by impressions that conceal the underlying tensions, as exemplified by the case of Volkswagen's 'dieselgate' scandal (Gaim, Clegg \& Cunha, 2019). In Wolfsburg, a façade masking a false mastery of paradox was constructed to manage impressions rather than emissions (see Chapter 4 for more details). Managing politically by deceit trumped managing paradoxes pragmatically. Berti and Simpson (2019) and Cuganesan (2017) also researched paradox from a power and politics perspective, noting that paradoxes' contradictions may create not so much politically virtuous cycles as ones that lose meaning and become illogical (Berti, 2021). Avoiding a Panglossian view of paradox, seeing all paradoxes as good (Berti, 2021), a more realist account of existential dilemmas in managing paradoxes was provided.

In summary, the trajectory of paradox scholarship by organization theorists transformed paradox from being seen as a sign of dysfunction, an incongruity, to a situational source of advantage, depending on the strategies and politics that represent and engage with paradox. Paradoxes are neither good nor bad; as opportunities they can lie fallow, be harvested or left to rot in situ. The politics of strategy for paradoxes pivots on deciding when and how to do which of these options in organizing imagined futures.

The 2020s: Exploring metatheoretical potential? Metatheory is based on a set of shared underlying assumptions, not confined to specific contexts, variables or methods underlying a theory. The concept describes a constellation of commitments to theoretical beliefs, values and techniques shared by a relevant scientific community. Paradox has lately been presented as a metatheory informing and enriching different theoretical streams capable of integrating 
a diversity of phenomena and interpretations within one broad framework (Abrams \& Hogg, 2004; Ritzer, 1990). Being a 'true' metatheory requires more than methodological variety: it implies providing an overarching perspective that can incorporate and inspire multiple approaches. A strong form of metatheory including methods, objects of interest and an exemplary body of knowledge is usually referred to as a paradigm (Ritzer, 1975), providing identity for a specific scholarly community.

Paradox may not yet be a paradigm, but it certainly constitutes an over-arching perspective, complementing existing theories by elaborating the role of contradiction, tension and opposition in different organizational processes. Poole and Van de Ven (1989) point out that most paradox researchers try to build internally consistent theories rather than auxiliary hypotheses. The search for consistency has resulted in less attention being paid to the potential for theory building related to phenomena characterized by tensions, oppositions and contradictions. Paradox theory functions as a metatheoretical perspective offering a broader conceptual framework which can bridge and interrelate multiple organizational theories that purposefully examine and surface tensions, as a heuristic device. Hence, it does not compete with other theories striving for paradigmatic dominance such as contingency, resource dependence, dynamic capabilities, neo-institutionalist theories, positioned as yet another analytical structure studying one particular set of phenomena (Shapira, 2011).

The boundary conditions for paradox scholarship exclude representations of phenomena that do not focus on tensions. Conceptual coherence is to be achieved by constructing a set of complementary and interrelated concepts that encompass different constitutions, manifestations and constructions of organizational paradox. The necessity of a variety of alternative foci - each coherent with a different onto-epistemological orientation - derives from the conceptual core of the theory, as defined by Lewis and Smith (2014): the existence of a dynamic duality between ontologically substantive tensions and their cognitively, socially (and politically) constructed manifestation as paradoxes.

In line with the idea that a paradox lens can be fruitfully employed not just to examine specific phenomena, but also to account for a whole range of complex social dynamics, Clegg, Cunha and Berti (2020) have proposed a conceptual model explicating the dynamics that regulate theory selection and retention in management and organization studies. They attribute the sustainability of a research programmes (e.g. contingency, institutional, resource-based perspectives) to the capacity of the research movement promoting it effectively to navigate paradoxical tensions that derive from efforts to organize the socio-material elements (grammars, thought styles, material artefacts and empirical craft) that underpin theorizing (Clegg et al., 2020). 


\section{ARE PARADOXES MATERIALLY REAL OR SOCIALLY CONSTRUCTED?}

An ongoing debate in the paradox literature refers to the ontology of paradox. The central question in this debate is: are paradoxes materially real or are they socially constructed? There are good reasons to defend the merits of both perspectives. Interdependent oppositions that persist as organizing efforts unfold need to be constructed as paradoxes, which does not always happen, either on the part of managers or researchers. People may live with competing demands without constructing them as paradoxical (Child, 2019). From the materialist perspective, which we review next, paradoxes are real in their effects even when they are not socially constructed as so being.

The materialist perspective. The materialist perspective treats paradox as belonging to the domain of the real, as a phenomenon with causal powers that will become manifest, irrespective of their cognition as such by actors. Realist approaches to paradox are grounded on the assumption that there is a material world independent of social constructions (Kilduff, Mehra \& Dunn, 2011). Paradoxes, in this regard, have real properties. Sometimes these realities are visible and graspable; other times they are 'unactualized propensities' (Ramoglou \& Tsang, 2016: 410) with a material base that exists in reality, albeit one that may be neither evident nor grasped. In such a grasp of paradoxes the role of organization decision makers is to be alert to the contradictions inherent in the real and invest in their recognition (Knight \& Paroutis, 2017; Tuckermann, 2018) as a source of competitive advantage.

From a materialist perspective, paradoxes originate in the realm of the real (Bhaskar, 1975) and exist regardless of their observation as such. When social totalities produce manifest contradictions between current and alternative possibilities (Benson, 1977) paradoxes may gain attention. Contradictions materialize at some point and become expressive, for example, in class conflicts or gender relations. From this perspective, the roots of paradox belong to the tangible world of materialities composed of contradictory elements. Any form of structurational goal conflict would be considered likely to produce paradoxes resulting from frictions occurring when latent causal powers or propensities become manifest. When treated as real, paradox is anchored in the world of phenomenal things: bodies and their relations with each other and with the actants of organizations, the materialities and structures framing them. As persistent processes, paradoxes may be latent and take place in the absence of clear cause-effect chains. For instance, gender relations were of little cognitive concern for management theorists in the era of the 'organization man' (Whyte, 1956) although class relations were recognized as being organized largely through pattern bargaining by organized labour (Levinson, 1960). Today, the 
situation is reversed as liberal political economy has reduced the salient identity of class relations and made gender relations an enhanced identity concern.

Contradictions are an inherent feature of complex systems, as discussed by authors in the tradition of systems theory (Boulding, 1956; Katz \& Kahn, 1978; Stacey, 1996). Systems complexity is seen as real-constitutive and the conflicting nature of those systems that create paradox is stressed. These systems are themselves composed of complex agents (Simon, 1996) whose competing goals necessarily produce divergence and contradictions that need to be tackled simultaneously; for example, change and stability (Farjoun, 2010) and exploration and exploitation (March, 1991). Tensions between these forces are structurally rooted as inherent features of systems that emerge from the complexity of the system itself (Schad \& Bansal, 2018). The lack of balance in the management of tensions sometimes becomes manifest in processes such as lack or excess of change (Langley et al., 2013), too little or too much innovation (Martin, 2009) or competing goals and worldviews originating in different organization silos or thought worlds (Leonard-Barton, 1992). From a paradox perspective these are all manifestations of organizational imbalance.

Paradoxes, as processes, are inherently temporal, unfolding, coming to be and passing away. While managers may express "little engagement with the future as fundamentally open" (Berg Johansen \& De Cock, 2018: 187), being unaware of latent paradoxes assuming manifest shape over time, it is likely because most of the systems to which they are held accountable have limited temporality. Institutionalized accounting schemes are tightly time prescribed. When processes are bracketed over short periods of time, as they often are, momentary paradoxes might emerge (Berg Johansen \& De Cock, 2018). Tensions and contradictions unfolding over significant intervals can be difficult to detect, even when their material roots are present, as appears to be the case with some democratic politics, such as the 2016 Brexit Referendum in the UK. The referendum concentrated multiple senses of tension and contradiction into a popular vote of perceived English subaltern protest, an electoral howl of outrage at being marginalized too much for too long, while in Scotland the tensions and contradictions coalesced around Brexit in quite different social constructions of national identity. People experiencing the effects of paradoxes do not necessarily grasp their materially deep mechanisms. When analysis zooms out to apprehend patterns it is often after the event (Schad \& Bansal, 2018). Ways of seeing that are habitually grounded in the routines of the present and its recent past often cannot discern distinctive features that become apparent in analytical retrospect after current events have faded.

Dealing with paradox implies awareness of the role of time and of temporal scale (Bansal, Kim \& Wood, 2018), the unfolding of being in the potentiality of becoming. The time scale of paradox renders inter-pole tensions difficult to perceive. Approaching paradoxes as temporal experiences in which that which 
is not immediately discernible, that which is latent, becomes manifest, implies a rare skill to render long-term projections concrete, a demanding exercise (Bansal, Kim \& Wood, 2018). More probable is that as organizations converge towards institutionalization and reinforce existing solutions, the tendency is to attend largely to just one of the demands, that which is most apparently immediate. Choices such as this, prioritizing one of two options, such as exploration or exploitation, exacerbate the need for the other (Sundaramurthy \& Lewis, 2003).

Paradoxes are inherent and cannot be ultimately solved (Putnam, Fairhurst \& Banghart, 2016); managing paradoxes implies what Andriopoulos and Lewis (2010: 106) denote as 'tapping their energy'. Paradoxes seen in these terms express the ontological quality of organizing, reflecting the deep structure of organizing as inherently political, pervaded by pluralism and antagonism. Because "pluralism is inherent to organization" (Clegg, 1994: 164), organizing implies tension. To summarize, paradox can be approached as materially real.

The constructivist perspective. From a social constructivist perspective intersubjectively contradictions perceived in reality may or may not categorize them as paradoxical: taken-for-granted realities are produced via intersubjective interaction (Fairhurst \& Grant, 2010). Here actors 'construct' their reality according to the 'psychological frameworks' they have 'evolved to make sense of' phenomena, rather than 'perceiving' some objective reality (Eden et al., 1981: 40). A valid interpretation of complex environments might be to anchor these realities in contradiction and tension. From an interpretivist, social construction perspective, reality is not some objective truth waiting to be discovered but an outcome of discourse and social interaction, leading to the coexistence of multiple realities in contests for legitimacy. Paradox is an 'in the eye of the beholder' type of phenomenon (Fairhurst \& Grant, 2010): language is formative of a sense of reality rather than corresponding to it; the representations used to frame reality shape the way phenomena are constructed. From this perspective, paradox's detection is attributional: people stamp paradoxical qualities on the complex realities with which they engage. Reality itself is not paradoxical unless represented as such, and where some see a paradox, others might see 'normalcy'.

Paradoxes, seen as social constructions, are a product of human practice and communication, rather than of material realities outside the realm of cognition, a central idea in the theorizing of authors such as Putnam et al. (2016) who stress how actors construct paradoxes communicatively in practice. Paradoxes are not produced by isolated individuals but through interactions made possible by public language shared, developed and legitimated by social relations (Hengst et al., 2020). In this view, a paradox is not revealed and made manageable unless it is constructed (Tuckermann, 2018) as such through practice. 
Paradoxes are embedded in social contexts, with actors making sense of them through socially collective construction.

\section{BOX 1.5 PARADOX, CULTURE AND INTERPRETATION}

In some cultures, some paradoxes may be perceived as less paradoxical than others, because they have become almost second nature, culturally accepted. For instance, a study of Chinese leaders indicated that a Chinese style of developmental leadership integrates authoritarian and benevolent features (Wang, 2019). This combination, unorthodox in other cultures, may be perceived as normal in China. Therefore, what others consider as involving a measure of tension and conflict may, in the case of Chinese leaders, be normal rather than contradictory. What is contradictory here, may be normal there.

Paradoxes also become manifest at more micro levels, without people necessarily constructing tensions as paradoxical or dangerous. As Bateson et al. (1956) explained, people may engage in relationships marked by communication patterns that lock individuals in problematic dynamics, such as double binds. In the double bind, two or more people regularly engage in communication patterns marked by injunctions that conflict with one another, such as 'You need to be creative!' and 'I will not tolerate mistakes.' In some contexts, such as those of power imbalances, subjects cannot escape these dynamics. The absurdity of the situation can be normalized as just another day at the office. Its effects, however, can be debilitating as individuals may not be able to escape this vicious circle that ends up creating Kafkaesque forms of organization (Clegg et al., 2016).

To summarize the social constructivist perspective, paradoxes are intersubjective accomplishments (Sharma \& Bansal, 2017) that are "talked into existence" (Lindberg, Rantatalo \& Hällgren, 2017: 175). The fact that, from a materialist perspective, they might be real does not necessarily render them transparent or explicit (Metcalf, 1940). In terms of social constructions, organizational structures will often be designed to address one element of a dialectical intertwining of paradoxical poles. For instance, they might focus on exploitation of what is known, secure in the here-and-now, while neglecting investment in exploration of innovation for the future. To aggravate the difficulty, it is even possible that, in some cases, the here-and-now focus is sufficiently successful as to override concerns about exploring for the future. The presumed 'resolution' of paradox, working well in the short run, leads to the inference that there 
is no paradox at all. For this reason, the social construction of a phenomenon as paradoxical should be taken as a deliberate and effortful endeavour.

Integrative views: the case of performativity. By contrast to dualist approaches, performativity denotes realities and their representations as simultaneously enacted or performed as a result of the interweaving of the social and the material. From this perspective, discourse and materiality are perceived as analytically inseparable and mutually entangled, neither having a privileged status over the other: "words constitute reality and affect organizational outcomes by creating a shared sense of reality that brings phenomena into being" (Lockwood, Giorgi \& Glynn, 2019: 23). A performativity perspective "shifts the focus from linguistic representations to discursive practices" (Barad, 2003: 807), helping to bridge the worlds of theory and practice, explaining the human/social and non-human/material interventions in the emergence of paradox.

The performative view explores how paradoxes are turned into reality through practice and how practice reinforces the reality of paradoxes. Meaning and matter are held together via the enmeshment of language, cognition and place, with practice mediating the relationship between the discursive and the material, which coexist as enmeshed facets of reality. Performing is an exercise in relational enactment through practice (Law, 2008). By taking practice as the primary building block of social reality (Feldman \& Orlikowski, 2011), paradox becomes seen as "something people do, rather than something that organizations have" (Guérard, Langley \& Seidl, 2013: 574). Such a notion helps with seeing how paradox is done as a process that people enact, rather than assuming it to be either already formed as a thing that people discover or as a construction of language and intersubjectivity. Practice brings paradox to reality via the mutual entanglement of words and deeds, in incessant recursive cycles in which contradictions are categorically framed and established categories are fulfilled.

\section{USES OF PARADOX IN ORGANIZATION STUDIES}

Paradox has been used in the literature in different ways (see Figure 1.1 and Table 1.1). In this section we organize these uses around three views: paradoxes viewed as descriptive, normative and instrumental. Descriptively, paradox is used to depict specific organizational phenomena; instrumentally, practitioners cope with paradoxes through particular paradoxical mindsets and agency and cognitive, structural and practical responses; normatively, paradox signifies the pros (and cons), both for theoreticians and strategists, of adopting a paradoxical frame of reference for making sense of reality. The perspectives offered by these three views are not incompatible, which means different actors can make use of more than one for different purposes. For example, 
the nurturing of a paradox lens can help organizational members discover prescriptive uses of the idea. As Lüscher and Lewis (2008) put it, paradox can change from label to lens and prescriptive uses can be derived from the lens.

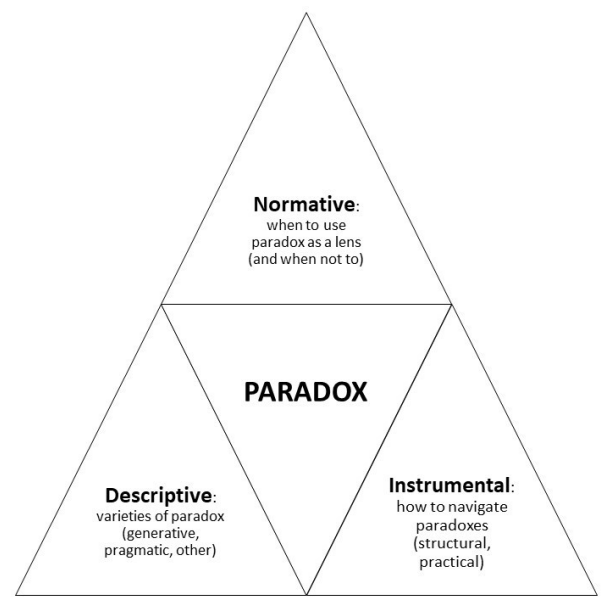

Source: Adapted from a figure proposed by Hahn et al., 2018.

Figure 1.1 Descriptive, normative and instrumental views of paradox

The descriptive view. This perspective aims to theorize the different types of paradoxes that exist 'out there', the operation of paradox (what triggers it, how it unfolds) and its consequences (circles, synergies). The descriptive role of theory consists in studying paradox to understand what it is and how it happens. This view resulted in important contributions that help to make sense of paradox as a phenomenon.

Work in this strand explains the origins of paradoxes as well as the process associated with managing, or not, paradox in organizations. It has helped with classifying different types of paradoxes along typological lines, such as those presented by Smith and Lewis (2011) and Berti and Simpson (2020). Smith and Lewis (2011) discussed four types of paradoxes, introducing nuance in the discussion of paradoxes. Berti and Simpson (2020) classified paradoxes with a logic that is sensitive to power dynamics, showing that paradoxes are not equal in their import and impact but also that some paradoxes can be debilitating. Pragmatic paradoxes, as they explained, can actually confront organizational members with impossible choices. In combination, work in this stream is helping to map the complexities and nuances of the paradox landscape. 
The normative view. Approaching paradox as an idea rather than as a thing (as in the previous case), the normative view extols the potency of paradoxical thinking in addressing complex organizational issues. Normative approaches stress the intrinsic value of paradoxical perspectives as a norm with which to tackle complex problems. As a lens, paradox offers a way of seeing that illuminates aspects of organizations and of organizational functioning obscured by other approaches to organizations. Seeing through paradox accentuates dimensions of organizing not necessarily considered in other perspectives, such as tension, contradiction and opposition. These aspects are seen as an inevitable part of organizing. In other words, regardless of the organizational process under consideration, it will inevitably be marked by these attributes. The boundary conditions limiting the idea of paradox are defined as complementary tensions in opposition. A normative paradoxical perspective helps with understanding cases in which forces that oppose one another also define one another (i.e. are interdependent). In cases in which tensions are independent, it is of little or no use.

The instrumental view. Instrumental approaches to paradox theory lead to prescriptive models for application, helping to change organizations, establishing connections between tensions and organizational outcomes, and thereby managing tensions for organizational advantage. To some extent the instrumental view derives from the normative but more as a tool rather than as an orienting idea. Paradox, as a possible source of competitive advantage, consists in the capacity for seeing and intervening in a world aware that dualistic thinking limits the ability to capture the ambiguities of experience. Instrumentally, paradox constitutes an invitation to intervene in a world inherently composed of opposites in tension, freeing organizations from the tyranny of 'either'-'or' choices (Collins \& Porras, 2005). By loosening such a conceptual straitjacket, organizations may help their members redefine organizations as spaces where opposite goals may be achieved - a need that becomes more relevant as organizations are urged to find synergies between different stakeholders with divergent needs (Tantalo \& Priem, 2016) in order to tackle grand challenges (Schad \& Smith, 2019). By applying a both-and type of reasoning to organizational and societal challenges, managers aim to find novel viable synergies to tackle important issues. Instrumentally paradox has been presented as a way of dealing with the world through an integrative mindset, one that rejects the simplicity of dualism. Some instrumental views of paradox have been advanced, including Johnson's polarity map (Johnson, 2014) and Smith, Lewis and Tushman's (2016) 'both-and leadership', presented as mechanisms for extracting synergies out of paradoxical tensions. 


\section{Table $1.1 \quad$ Uses of paradox in organization studies}

\begin{tabular}{|c|c|c|c|}
\hline & Descriptive & Normative & Instrumental \\
\hline Goals & $\begin{array}{l}\text { To represent paradox as } \\
\text { it happens in the 'real } \\
\text { world' }\end{array}$ & $\begin{array}{l}\text { To define when to use } \\
\text { paradox and when not } \\
\text { to do so }\end{array}$ & To guide intervention \\
\hline Expressions & $\begin{array}{l}\text { Typologies, process } \\
\text { models }\end{array}$ & Conceptual clarifications & $\begin{array}{l}\text { Tools, practical } \\
\text { indications }\end{array}$ \\
\hline Target & Mainly academics & Mainly academics & $\begin{array}{l}\text { Mainly practitioners and } \\
\text { consultants }\end{array}$ \\
\hline Limitations & $\begin{array}{l}\text { May create perception of } \\
\text { paradox as too abstract }\end{array}$ & $\begin{array}{l}\text { May create hard-to-define } \\
\text { boundaries between } \\
\text { contiguous concepts }\end{array}$ & $\begin{array}{l}\text { May transmit the idea } \\
\text { that paradoxes can be } \\
\text { controlled }\end{array}$ \\
\hline Representative work & $\begin{array}{l}\text { Smith \& Lewis (2011) } \\
\text { Berti \& Simpson (2020) }\end{array}$ & $\begin{array}{l}\text { Lüscher \& Lewis (2008) } \\
\text { Smith, Lewis \& Tushman } \\
\text { (2016) }\end{array}$ & $\begin{array}{l}\text { Collins \& Porras (2005) } \\
\text { Johnson (2014) }\end{array}$ \\
\hline
\end{tabular}

\section{CONCLUSION}

Once upon a time, paradox was perceived as an organizational disease, a sign of malfunction. No more. In contemporary times organizations are commonly described as 'rife with paradox' because "ontologically, organizations are multidimensional, socially constructed realities where different aspects can coexist in complementary, conflicting, hence paradoxical ways" (Morgan, 2011: 467). Initially, as we reviewed the field for this chapter, paradox was represented as a something to be 'solved', to be neutralized. Subsequently, managing paradox became a talisman of success with which to take advantage of the synergies contained in tension and opposition. The foe became a friend. Yet, even when seen as normal, as a part of what organizing implies, paradox can be hard to tackle. The tensions that paradoxes reveal lead as easily to the erection of psychological and social defences against these as to bold embraces in managing them. Some tensions may simply be repressed, forcing people to pretend that they do not exist. Mikkelsen and Wahlin (2020), researching diversity management in the local branch of a global retail chain, found this to be the case. A dominant narrative of diversity impeded people from critically expressing their views so that in the name of diversity, diverse opinions were silenced! These tensions reflect the nuance of paradox, including its absurd dimension, which is where we begin the next chapter. Paradox may be part of the manager's toolkit - but still be difficult to master. 